\title{
Mathematical sense-making through learner choice
}

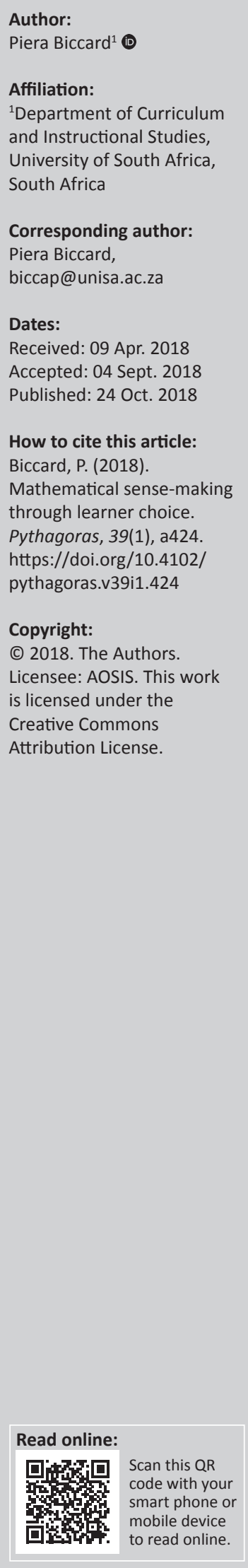

This article explores a conceptual relationship between learner choice and mathematical sensemaking. It argues that when learners can exercise choice in their mathematical activities, mathematical sense-making can be enhanced. The literature around mathematical modelling suggests a link between sense-making and learner choice. A three-tiered conceptual analysis allowed 'purposiveness to thinking' from the author through engagement with selected literature. Research questions related to a three-tiered analysis: generic, context-specific, and conditional accounts of sense-making in mathematics classrooms were formulated. The analysis resulted in a framework showing how sense-making may be constrained or enhanced in mathematics classrooms through learner choice. This article may add to our holistic understanding of sense-making in mathematics classrooms. It may contribute to mathematics teacher education by proposing that teachers are resourced to facilitate learners' conceptual and procedural choice in primary or secondary mathematics classrooms.

\section{Introduction}

Learners often view learning mathematics as non-sense-making (Dienes, 1971; Schoenfeld, 1991). Non-sense-making is distinct from nonsense (no meaning is possible) and is closer to the term senseless (having no meaning). Schoenfeld (1991, p. 316, 320) coined the phrase 'suspension of sensemaking' or 'significant nonreason in students' school mathematics' to describe learners' disengagement with mathematics. The senselessness experienced by learners when trying to engage with mathematics may stem from a disconnection between the learners' procedural and conceptual understanding. Teachers also mistake procedural competency for conceptual understanding where they see the latter as a natural consequence of the former. Often the senselessness of mathematics comes from this assumption, especially when the problem changes from 'basics' (manipulation) to 'application' (word problems). Curricula are also often set up to mask procedural ability for conceptual understanding.

Reusser (2000) explains that non-sense-making takes a number of forms such as learners finding answers to unsolvable problems, for example 'There are 125 sheep and 5 dogs in a flock. How old is the shepherd?' (p. 23), or students using keyword strategies inflexibly, for example always adding if the word 'more' is in the problem. Another area where sense-making is suspended is in realistic contexts. In reality-based problems the numerical answer needs to be interpreted against the real context (e.g. calculating that ' 5 remainder 2' buses are necessary to transport a group of people. Very few primary school learners reinterpret the 'remainder 2 ' as the need for a sixth bus). For Schoenfeld (1991) many hours of completing worksheets with similar format have a significant effect on non-sense-making. If teachers want to assist learners' sense-making they need to help them experience acts of sense-making (Sierpinska, 1994). Blind application of procedures (Schoenfeld, 1991) makes it very difficult for learners to be involved in authentic sense-making.

Mathematics teachers would like to see learners engage in mathematical sense-making. The term 'sense-making' is often interwoven with ideas of deepening understanding and application of mathematical concepts (Van Velzen, 2016). This article uses a conceptual approach to explore learner choice as a property of sense-making. It proposes that choice may elicit enhanced understanding and application of mathematics. The author, therefore, tries to draft a 'programmatic description' (Scheffler in Soltis 1978, p. 9) of what should take place in mathematics classrooms. This may contribute to the field by simplifying the necessary conditions for promoting sensemaking in mathematics classrooms. This article is not a full description of sense-making but rather proposes a certain way of looking at sense-making in mathematics classrooms through the role of learner choice. Furthermore, this article proposes that learner choice may be a feature of sense-making in mathematics classrooms.

For Weick, Sutcliffe and Obstfeld (2005) sense-making is explicit and individuals create understanding through a retrospective reflection on decisions and actions. In contrast, Klein, 
Moon and Hoffman (2006) argue that sense-making can precede actions since 'sensemaking is a motivated, continuous effort to understand connections (which can be among people, places and events) in order to anticipate their trajectories and act effectively' (p. 71). The stance of the author is that both ideas may be useful. Learner decisions and actions may affect sense-making in mathematics classrooms both prospectively and retrospectively. This article asks the question 'Can learner choice enhance sense-making in mathematics classrooms?' Perhaps learner choice and sense-making are circular and not linear ideas, that is, they inform each other.

The quote 'Any mathematical experience in which students make choices about how to use mathematics to create representations of a real-world process is a form of mathematical modeling' (Gann, Avineri, Graves, Hernandez, \& Teague, 2016, p. 97) led to the author's interest in exploring learner choice in mathematics classrooms.

Since mathematical modelling led to the ideas in this article, a brief definition is necessary at this point. The definition of Lesh and Doerr (2003) is that models are:

conceptual systems that consist of elements, relations, operations and rules governing interactions that are expressed using external notations system and that are used to construct, describe, or explain the behaviours of other systems - perhaps so that the other system can be manipulated or predicted intelligently. A mathematical model focuses on structural characteristics (rather than for example physical or musical characteristics) of relevant systems. (p. 10)

Model-eliciting problems are reality-based problems where the product that learners are required to create or design will elicit a model of/for the problem.

Modelling is known to increase sense-making (Lesh \& Doerr, 2003; Lesh, Yoon, \& Zawojewski, 2007). This article argues that one of the reasons why modelling supports sensemaking is because model-eliciting problems provide avenues for learner choice when using or creating mathematics. When purely procedural methods are drilled, learners are passive in exercising agency and choice. What does it mean to have a choice? Generally, it means both the act of choosing (to select) and the power of choosing (having an option) (MerriamWebster online dictionary).

The idea of decision-making, freedom or choice is also considered by other scholars in mathematics education. Polya's (in Kilpatrick, 1985) earlier seminal work on problemsolving classification ranked problems according to the degree of choice the learners have in solving the problem. Freudenthal (1991, p. 117) conceptualised the term 'spontaneous differentiation' where students choose for themselves at which level they will work, rather than 'imposed differentiation', where a teacher decides in advance at which level or with which methods the students will work. Other realistic mathematics education scholars
(Gravemeijer, 1994a; Treffers, 1987) echo the importance of differentiation based on learners using their own methods (which implies learner choice).

Terms such as 'own methods' are considered to be consistent with learners being allowed to make decisions or have choice when solving problems. Hiebert et al. (2003) cite that learners benefit from choice in solving problems and documented this aspect in the TIMSS video analysis study. Hiebert et al. (1997, p. 24) also point out that as a result of students using their own methods they develop general approaches for inventing specific procedures or adapting ones they already know to fit new problems'. Fosnot, Dolk, Zolkower, Hersch, and Seignoret (2006) consider teacher facilitation of learners' own mathematical constructions as an advanced form of pedagogy as do cognitively guided instruction scholars (Franke, Carpenter, Levi, \& Fennema, 2001). Stein, Engle, Smith, and Hughes (2008) set out how important it is for teachers to use learners' own methods to build connections between important concepts.

What does learner choice look like in mathematics classrooms? Learner choice entails learners being in the driving seat of the methods, procedures, representations and explanations in the mathematics class. Learners will have the option of entering a problem from their knowledge base, tackling the problem using their own 'mathematical toolbox' (Jensen, 2007, p. 144). The teacher will then facilitate vertical mathematisation (connecting and developing more abstract mathematical ideas; see Treffers, 1987) through focusing on connections between the various approaches used by learners. This means that the learners build a 'floating capacity' (Webb, Boswinkel, \& Dekker, 2008) of the abstract concept. Floating capacity from an iceberg metaphor refers to the many informal representations of an abstract concept while the tip of the iceberg is the concept in abstracted form. The floating capacity develops and supports the understanding of the tip.

This article is structured in the following way. The section on method and research questions provides some discussion of the method followed for the analysis of the concepts under scrutiny. It also sets out the questions that were formulated in undertaking the study. The section that follows the method focuses on the occurrence of sense-making in mathematical classrooms generally. It is followed by a section looking at a specific mathematical activity, that is, modelling, focusing specifically and descriptively on what features of modelling activities support learner choice to enhance learner sensemaking. Following this, some basic tenets for sense-making in mathematics classrooms are proposed. The final section concludes with a possible framework provided by the author for understanding sense-making through learner choice in mathematics classrooms.

\section{Method and research questions}

Bousso, Poles and Da Cruz (2014) explain that it is important to engage with concepts because they are used to develop 
theory, they can be operationalised and they can enhance practice. Wilson (1963) explains that understanding concepts is not related to facts, values, definitions or meanings of the words but rather about the actual and possible use of the words and their 'logical mystery' (p. 13). Soltis (1978) set out three features for the analysis of education concepts. He proposed a generic analysis (what features must $X$ have to be called $X$ ?), a differentiation analysis (what are the different basic meanings of $X$ ?) and a conditional analysis (what context conditions govern the use of $X$ ?). In this article, Soltis's scheme was adapted and abridged and provided some ideas for method and logical structure of the article in three related parts. For this article, the three-part analysis comprised a generic analysis, a context-specific analysis and a conditional analysis. The three-part analysis allowed the researcher to explore a conditional relationship between learner choice in mathematics classrooms and their sensemaking. The analysis is interpretive and non-technical and begins by the researcher setting out a premise (Kahn \& Zeidler, 2017) (in this case: learner choice is a property of sense-making). A conceptual analysis allows one to unpack central constructs in an area under investigation (Kahn \& Zeidler, 2017). To unpack the central constructs, the following three questions were formulated.

In this article, a generic analysis seeks to answer the question: What are some of the features related to sense-making in mathematics classrooms?

According to Soltis (1978), the first step is to draw from general knowledge some general features. Various scholars have described sense-making using a range of terminology and examples. The current study undertakes to distill some common features of sense-making through the generic analysis.

A context analysis will then answer the question:

What features of mathematical modelling support learner choice and contribute to sense-making?

In this case a context-specific analysis only is done. This article will focus on sense-making in one particular type of task - mathematical modelling. In this section, mathematical modelling as a specific type of mathematics activity is described and analysed for features of enhanced sensemaking.

A conditional analysis will answer the question:

Under which conditions can it be said that sense-making may be enhanced in mathematics classrooms?

Soltis (1978) explains that the point of departure of a conditional analysis is to puzzle over the 'context appropriate for the use of the concept' (p. 104). In this study, some necessary conditions for enhancing sense-making in mathematics classrooms were considered based on the generic and context-specific analysis.
These questions were answered through engagement with selected literature on mathematical modelling and sensemaking. This engagement allowed 'purposiveness to thinking' (Wilson, 1963, p. ix). The centrality of learner choice in mathematical sense-making is an idea from Gann et al. (2016) who linked choice to mathematical modelling. The author of this article undertook to determine if learner choice is a general element of sense-making in mathematics. In order to understand the role of learner choice in sense-making, the terms sense-making, choices and decision-making were located in mathematics education literature. This assisted in 'the process of becoming conscious' of the meanings of words (Wilson, 1963, p. 15). However, the literature review led to exploring words beyond 'choice' or 'decision-making' to words such as 'modelling', 'problem-centered learning', 'informal methods' and 'flexible thinking'.

\section{Which features relate to sense- making in mathematics classrooms?}

Teaching and learning as explicated by Brousseau (1997) in the theory of didactical situations forms the basic theoretical tenet of this article. Brousseau elaborates on a 'didactical contract' that exists in mathematics classrooms. In many cases, teachers take the responsibility of showing or explaining mathematics to learners (and where the learners are expected to copy, memorise and repeat what they are shown). At the same time learners expect the teacher to show or explain. This, however, affects the level of knowledge, skill and understanding that the teacher wants the learner to achieve since the teacher is doing the mathematical work in the classroom. Schoenfeld (1992) states that when learners experience mathematics as having to follow a single procedure the teacher has in mind (traditional didactical contract), they will experience mathematics as a discipline that does not always make sense. Brousseau suggests that problems should be devolved through an adidactical situation. The teacher creates a new milieu in which problems are handed over to learners. The learners have to accept the responsibility for solving the problems knowing that the teacher has set the problem with an aim of learning something specific. This is similar to Freudenthal's (1991) conception of learners having to 're-invent' mathematics for themselves through teacher guidance. In general terms, to devolve a situation or a problem means to 'pass on (something, such as responsibility, rights, or powers) from one person or entity to another' (Merriam-Webster online dictionary).

This section looks at different conceptions of sense-making in mathematics classrooms. The analysis looks at various definitions and conceptions of what sense-making could look like in mathematics classrooms. Schoenfeld (2014) surmised that sense-making is about perceiving structure. The National Council of Teachers of Mathematics (NCTM) defined sensemaking more generally as 'developing understanding of a situation, context, or concept by connecting it with existing knowledge' (NCTM, 2016, p. 1). Sense-making is more about flexible application of mathematical knowledge (Van Velzen, 2016) than it is about performing procedures. 
In mathematics classrooms sense-making can be compromised by learners' inflexible concept cores (Trzcienieka-Schneider, 1993). According to Trzcieniecka-Schneider (1993), 'people with more plastic concept cores have higher consciousness of cognitive control of events' (p. 258). Increased concept flexibility could be developed by encouraging learner choice and explaining their choices. Trzcienieka-Schneider, citing earlier research where 98 learners solved ill-formulated problems, acknowledged that when pupils are discouraged from looking for their own (possibly unconventional) methods and examples, they develop stiff concept cores.

Tabachneck, Koedinger and Nathan (1994) explain that the abstraction process of formal mathematics is often nonsensical and that following rote procedures can lead to errors. Informal strategies (such as those students invent on their own) have been suggested for sense-making in mathematics classrooms (Gravemeijer, 1994a; Schoenfeld, 1991; Tabachneck et al., 1994; Treffers, 1987). Informal strategies, in particular, are more flexible (Tabachneck et al. 1994) and suggest a degree of learner choice. Dewey (1910, pp. 64-65) set out the concept of 'freedom' which could be akin to the concept of choice. He considered freedom as being capable of independent thought without the 'leading strings of others' (not following teacher presented methods). He furthermore set out that freedom is the 'ability to turn things over'. If learners are encouraged to explore concepts from their own and different vantage points, it may allow them to 'turn things over'. Boaler (2016, p. 189) also refers to intellectual freedom as learners using intuition to develop new perspectives on mathematical and 'transform their relationship with learning'.

Schoenfeld (1991) sets out how teacher 'assistance' and 'structuring' (leading strings) result in a procedural and nonsensical routinising of mathematics. Teacher assistance comes in the form of limiting the vocabulary used or teaching a 'key word method' (p. 323). Sometimes the rules teachers use do not make sense, but learners know that if they use them, they will get the 'right' answer. This perpetuates the idea that mathematics is about passively following rules that do not need to make sense. Boaler (2015) stated that learners who are taught passively 'do not engage in sense making, reasoning, or thought ... and they do not view themselves as active problem solvers' (p. 40). Nieuwoudt (2015) found that when Grade 4 learners (who initially displayed negative attitudes to solving word sums) were encouraged to solve word problems collaboratively, they were able to come up with different methods and were able to make sense of general problem-solving models. Schoenfeld summarises that advanced sense-making is evident (irrespective of the age level or content) where the teacher does not provide answers in advance, various methods (elicited by the learners) are compared and mathematical understanding is arrived at by social consensus.

The Teaching for Robust Understanding framework (Schoenfeld, 2016) encompasses what is proposed as a sense-making framework that can be used in any mathematics classroom.
Although it is beyond the scope of this article to discuss the framework in detail, a brief synopsis is presented. The framework was developed after Schoenfeld and colleagues considered many aspects of what should be present in mathematics lessons that promote 'robust understanding'. They analysed existing frameworks and distilled certain foundational ideas. Their framework comprises five dimensions (Schoenfeld, 2016). A mathematics dimension that considers how connections are forged between procedures, concepts and contexts. A cognitive demand dimension, that relates to the opportunities students have to make sense of mathematics through being challenged appropriately. The equitable access to content dimension focuses on who takes part in mathematics classroom discussions and how active engagement of all students is supported while the agency, ownership and identity dimension considers the opportunities that learners will have to see themselves as mathematical thinkers. The final dimension of formative assessment focuses on how students' current thinking is used to develop mathematical ideas. Learner choice may be relevant to each dimension. The mathematics content and the cognitive demand should allow learners to engage with concepts that are rich in connections. This means learners should be able to enter the mathematical discussion from their own perspective. Furthermore, learners should be introduced to the ideas of other learners. This promotes equitable access to content. Learners who are allowed to make choices of method, procedures and representations and have the opportunity to explain their reasoning develop identities of themselves as mathematical thinkers. Eliciting learner thinking through challenging tasks that are rich in mathematical connections allows teachers to use and develop learner ideas.

In summary, learners should be involved in 'doing the mathematics' in mathematics lessons. Tasks that promote active mathematical thinking by encouraging learners to use their own informal methods before memorising procedures are necessary for sense-making.

\section{Which features of modelling support learner choice and contribute to sense-making?}

Some features of mathematical modelling as they relate to learner choice and sense-making are presented in this section. The first feature of modelling is that problems are devolved. Model-eliciting problems typically include a messy realworld situation where students make assumptions and limit the information they use based on these assumptions. Handing over problems and the responsibility for solving them implies that these decisions and choices are also handed over to students. Blomhoj and Jensen (2007, p. 49) hold that the dilemma of 'teacher directed autonomy' needs to be overcome and the students need to be responsible for most of the decisions.

The second feature of modelling that relates to learner decision-making is that the starting and ending point for 
problems is reality. Cirillo, Pelesko, Felton-Koestler and Rubel (2016) differentiate mathematical modelling from modelling mathematics. This is an extension of Lesh et al.'s (2007) Deweyian conceptions of making mathematics practical versus making practice mathematical. Many learners experience modelling mathematics in their classrooms but not mathematical modelling. For Cirillo et al. modelling mathematics takes place when teachers find something in the world (contexts, representations etc.) on which to model the mathematics they want to teach - so the process starts in mathematics (e.g. using blocks or a number line to teach subtraction). On the other hand, mathematical modelling entails starting in the real world (with a problem) and then finding, choosing or creating mathematics (a model) that allows us to understand some aspects related to the structure of the problem. The following example of a modelling problem may assist the reader who is unfamiliar with them. Big Foot (Lesh \& Doerr, 2003) is a model-eliciting problem where learners (working in groups) are given a shoeprint measuring about $50 \mathrm{~cm}$ in length. They are given the task of explaining to the police what this person's height could be. Learners need to create a model from which the police can determine anyone's height from their shoe print. This problem can be used across many grades and age groups since the choice of mathematics is open to learners. The learners will use the mathematics that they are capable of applying. Furthermore, learners have the choice of which aspects of reality to include (do they consider only adults or only tall people in their measurements? What do they do with outliers?), which methods to use and what forms of representation to create (tables, graphs etc.). For Bliss and Libertine (2016, p. 12) 'a modeling problem must also provide room for students to interpret the problem and have choices in the solution process'. One of the strengths of mathematical modelling tasks is that they reveal what situations learners can mathematise and what previously taught mathematics they can apply.

The third feature of modelling where learner choice is embedded is that learners produce a model and do not only apply known models. This means that learners create models of other systems. With model-eliciting activities, teachers provide learners with a system (usually real) and through the question about that system ask learners to create a model in order to solve a problem about that system. Reiley (2017, p. 446) concludes that 'students should be able to make decisions about what they are presenting as the product of their task'. In producing a model, learners do not (necessarily) follow known procedures; they do not always apply a known method to a problem and find an answer in two steps. Modelling is a structuring process to deal with a problem where a genuine search for meaning is necessary. The problems are open and pathways are many. Learners need to discover relationships first, before finding the variables to describe them (Treilibs, Burkhardt, \& Low, 1980).

Gann et al. (2016, p. 105) explain that the focus of mathematical modelling is not to learn (or make sense of) a specific mathematical topic, but it is 'learning to make decisions and assumptions and on using mathematics to understand a real-world-scenario'. Treilibs et al. (1980) found that poor modellers avoid decisions of any sort entirely. This may be because they are not exposed to decision-making in mathematics classrooms that are teacher-centred and teacherdirected. When they are exposed to open problems that need structuring they are unsure how to proceed. This decisionmaking feature of modelling may be central to learner sensemaking.

A fourth feature of model-eliciting problems that encourages decision-making and supports sense-making is that learners work in groups. Competencies of the group are likely to be greater than those of individuals (Hatano, 1996; Zawojewski, Lesh, \& English, 2003) since working with others encourages spontaneous verbalisation (Artz \& Armour-Thomas, 1992). Mathematical sense-making can be seen as being distributed (Pea, 1993) across learners, representations, explanations, materials and tools in the group activity. An important feature of any group work is the concept of 'negotiation' (Lave \& Wenger, 1991). Weick et al. (2005) state that sensemaking is 'an issue of language, talk, and communication' (p. 409) where a 'share[d] understanding ... lift[s] equivocal knowledge out of the tacit, private, complex, random and past to make it explicit, public, simpler, ordered and relevant to the situation at hand' (Obstfeld, 2004, in Weick et al., 2005 , p. 413). In model-eliciting problems, the space is complex and necessitates discussion and decision-making collaboration with others which may contribute to enhanced sense-making.

A final feature of modelling is that learners make use of their own ideas. Authors such as English and Watters (2004) and Hamilton (2007) propose that even young learners and learners who do not have the necessary ready-made mathematical tools can be involved in mathematical modelling. Hamilton contends that learners will invent their own version of the tools because they have decided that these tools are necessary. Learners will decide which tools to use or invent. In modelling mathematics, the teacher makes the choices regarding relevant concepts and procedures for the learners, while in mathematical modelling, the learners structure and model the messy complex problem. When learners create their own tools and representations to solve problems, this process may enhance sense-making. Modelling requires that learners make choices about the problem context as well as the mathematics that can be used to solve it.

The features of modelling that contribute to learner choice and enhance sense-making can be summarised as: problems in their entire complexity are devolved (handed over) to learners, problems are set in authentic realistic contexts (where learners make their own assumptions), learners produce a model and learners use, create or decide on the tools they need. Modelling involves more competencies than only being able to follow set methods and procedures. Furthermore, learners work collaboratively in groups in what is largely a decision-making process. 


\section{Under which conditions can sense- making be enhanced in mathematics classrooms?}

A conditional analysis for the context conditions for which sense-making may be enhanced is now considered. In mathematics classrooms, the context conditions discussed in this section are the type of problems learners solve, as well as the classroom environment. Mazur (2013) makes a clear distinction between contextual problems that are authentic or non-authentic and the impact of these on sense-making in classrooms. His concepts are similar to modelling mathematics and mathematical modelling (Cirillo et al. 2016). According to Mazur, a non-authentic contextual problem has the form as indicated in Figure 1 where a known procedure is used to solve the problem.

The given problem has an unknown answer that can be found using a known procedure. Learners simply recall the correct formula and apply it to the problem once they have removed the words in the problem. It may not necessarily be 'the answer' per se that is unknown, but also not knowing that the answer is justified or suitable. This is evident when learners give senseless answers to problem contexts (e.g. giving an answer of $7 \frac{1}{2}$ people).

When Mazur defined authentic problem solving, he explained that the problem has a known outcome but the solution path is unknown (see Figure 2).

For Kramarski, Mevarech and Arami (2002, p. 226) authentic tasks 'can be approached in different ways ... and often ask solvers to use different representations in their solutions'. These differences infer learner choice in their approaches and representations. Mazur (2013) also explains that it is deceptively easy for a teacher to move authentic problems to non-authentic problems through limiting the choices and assumptions learners need to make. The process is subtle and often teachers are not aware of the consequences of

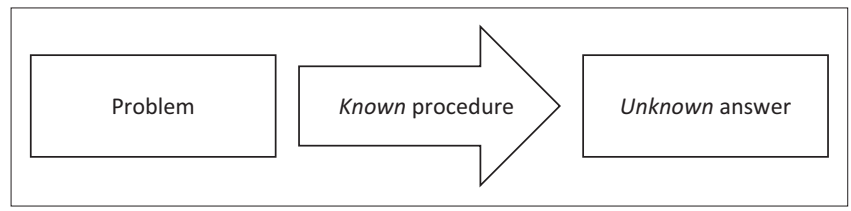

Source: Adapted from Mazur, E. (2013, October). Assessment, the silent killer of learning Dudley Herschbach teacher/scientist lecture, Harvard University, Cambridge, MA. Retrieved from https://www.youtube.com/watch?v=CBzn9RAJG6Q

FIGURE 1: Non-authentic problems.

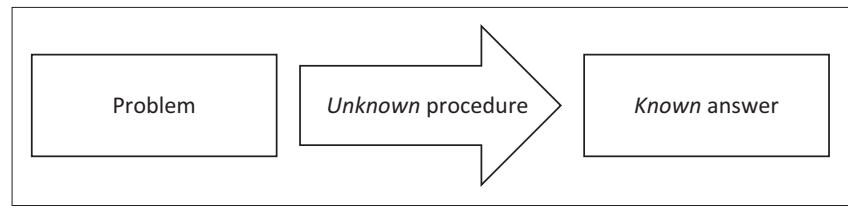

Source: Adapted from Mazur, E. (2013, October). Assessment, the silent killer of learning Dudley Herschbach teacher/scientist lecture, Harvard University, Cambridge, MA. Retrieved from https://www.youtube.com/watch?v=CBzn9RAJG60

FIGURE 2: Authentic problems. adding some structure to a problem. Structuring comes in the form of providing assumptions, suggesting which parts of the problem are significant or even reminding students of a formula. For example, if Big Foot is an authentic problem, a teacher could assist learners to get started by suggesting that they measure their own feet and heights and to calculate how many of their foot-lengths fit into their height instead of learners deciding that this is an option. The teacher can also remind the learners that a ratio can be calculated by dividing height by foot-length. If learners struggle with this, the teacher eventually 'assists' by providing a table of different heights and foot-lengths and learners simply have to divide them. This is how a didactic transposition (Chevallard, 1989) takes place on a micro level. When teachers impose structure on the problem, it constrains the decision-making and choices learners have. This may tie in with Brousseau's formulation of the didactical contract. Mathematics teachers often feel compelled to maintain their show/explain/assist role in the classroom. With limited learner choice, sense-making is relegated to remembering and applying at most and Boaler reminds us that learners who experience mathematics as remembering 'are the lowest achieving in the world' (Boaler, 2015, p. 41).

According to Mazur (2013), opportunities for learners to practise sense-making and decision-making are lowered every time teachers 'help' and every time teachers remove the higher-order levels of the problem because it is too messy for learners. This entails narrowing down learner choice. Decisions around structuring of problems and the trade-off of these decisions may affect the level of interpretation and sense-making.

In terms of a classroom environment that supports sensemaking, Schoenfeld (1991) asserted that the development of 'meaningfulness and understanding comes from interaction and negotiation and that that process is inherently social' (p. 339). Boaler (2015) explains that when learners have to work silently in mathematics classrooms, they do not provide their own ideas or perspectives. Boaler clarifies that mathematical discussions enhance sense-making because 'reconstruction deepens understanding' (p. 50) while Leatham, Peterson, Stockero and Van Zoest (2015, p. 5) emphasise that 'using student thinking to further mathematical understanding typically involves verbal interactions.'

Treffers uses the term 'interactivity' (1987, p. 249) which means that learners work with or alongside other learners. He maintains that the productions and constructions of other learners could stimulate learners to either shorten their own path (vertical mathematisation) or to become aware of positive or negative aspects of their own ideas. It may also make learners aware of other options they had in solving the problem or in solving similar problems in the future. In describing interactivity, Gravemeijer (1994b) says: 
explicit negotiation, intervention, discussion, cooperation, and evaluation are essential elements in a constructive learning process in which the student's informal methods are used as a lever to attain the formal ones. (p. 451)

The constructive learning process may come about through group collaboration, since it promotes 'students' mathematical understanding by creating opportunities for students to reexamine the validity of their reasoning' (Francisco, 2013, p. 434). Working within a group situation or sharing ideas of other learners further provides learners with avenues to connect mathematical ideas by reflecting on the choices made by other learners.

Boaler (2015) summarised the problems in mathematics classrooms as: learning without thought, learning without talking and learning without reality. This article proposes that learning without choice may underpin all three.

In summary, problems where the solution procedure is not always known and explicitly followed may enhance sense-making in mathematics classrooms. Problems that are so tightly structured that only one possible method can be used may also limit sense-making. The role of group processes may encourage sense-making since learner choice needs to be negotiated and validated by members of the group.

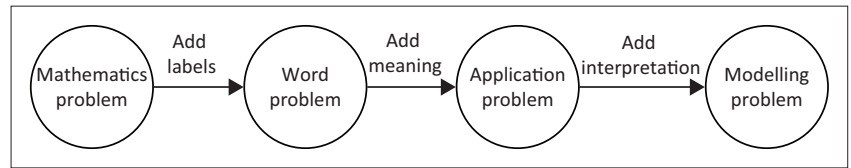

Source: Adapted from Bliss, K., \& Libertini, J. (2016). What is mathematical modeling? In S. Garfunkel \& M. Montgomery (Eds.), Guidelines for assessment and instruction in mathematical modeling education. Bedford, MA: Consortium for Mathematics and its Applications (COMAP) and Society for Industrial and Applied Mathematics (SIAM) (pp.7-22). Retrieved from http:// www.siam.org/reports/gaimme-full_color_for_online_viewing.pdf

FIGURE 3: One way of transforming a mathematics problem into a modelling problem.

\section{A possible framework for conceptualising sense-making through learner choice in mathematics classrooms}

Bliss and Libertini (2016) conceptualised how mathematics problems can be developed into modelling problems through a process of adding labels, meaning and interpretation as in Figure 3.

In this additive process, the problem is being opened up to allow for learning, interaction and sense-making through adding interpretations, meanings and labels. An example of this process may be that the mathematics problem is to

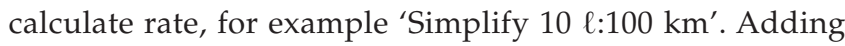
labels would lead to a word problem, for example 'A car uses $10 \ell$ of fuel for every $100 \mathrm{~km}$; at what rate is fuel consumed?' If some meaning were added: 'Dan is choosing between two cars and wants to buy the car with better fuel consumption. Car A uses $11 \ell$ per $120 \mathrm{~km}$ and car B uses $12 \ell$ per $130 \mathrm{~km}$. Which car offers better fuel consumption?' A modelling problem may involve asking if crossing a border to the next country $20 \mathrm{~km}$ away for cheaper fuel is worth the effort.

A possible explanatory framework that extends their diagram and that can help us think about sense-making through learner choice is presented in Figure 4.

Figure 4 shows how a mathematics problem can be opened up to allow for learner choice. With the added meaning and interpretation comes an increased potential for learner choice thereby possibly increasing learner sense-making. However, Mazur (2013) showed that it is possible to reverse the process and limit the assumptions, choices and sense-making of a

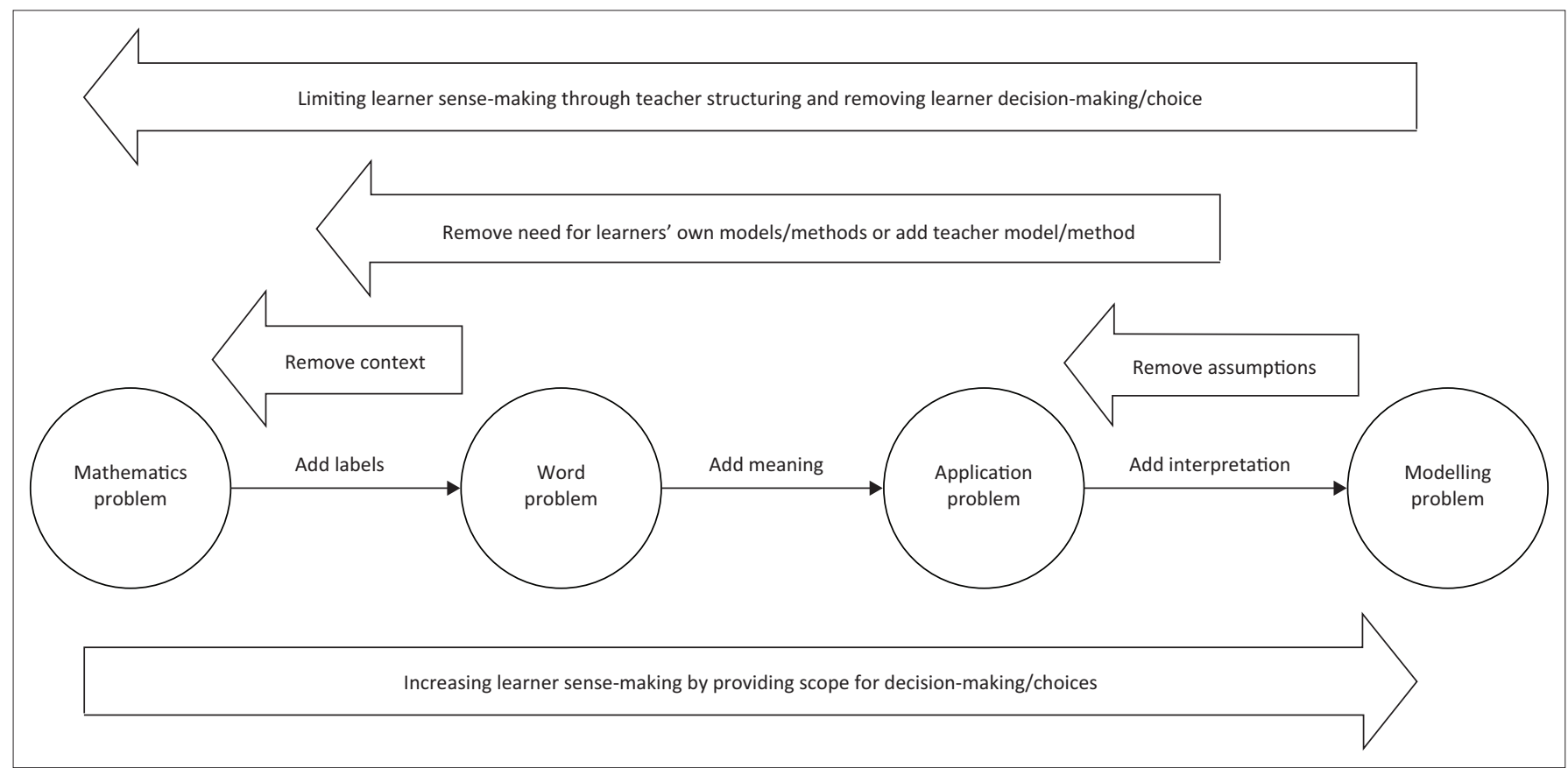

FIGURE 4: Supporting sense-making through learner choice. 
modelling problem by restricting learners' access to a messy real-world problem. This reversal is shown as removing assumptions from the problem, adding a teacher method or model and removing the context of the problem. In the above fuel consumption example, if the modelling problem is structured by the teacher, the assumptions learners need to make are provided by the teacher, for example the size of the fuel tank, the price of fuel, and so on. The teacher may further suggest a method (e.g. first calculate how much it will cost to travel $20 \mathrm{~km}$ to the next country, etc.) and so the move from a modelling problem to a word problem may take place. Practically, teachers and researchers may be able to use the framework to gauge to what extent lessons or lesson activities may be open enough to allow for learner choice and enhanced sense-making. The framework may also assist teachers or researchers to develop existing tasks to enhance the sensemaking potential of the task. The framework may also be used to reflect on classroom observations. Further work in developing rubrics or observation guides based on the framework may also be useful. Questions around the level of interpretation need to be asked while also exploring who is making assumptions or who provides the models in the classroom.

\section{Conclusion}

The NCTM (2016, pp. 3-4) sets out that sense-making in mathematics classrooms depends on 'worthwhile tasks that engage and develop students' mathematical understanding, skills and reasoning, a classroom environment in which serious engagement in mathematical thinking' takes place and where 'purposeful discourse' aimed at encouraging sense-making is evident. Sense-making takes place through active learner engagement with concepts and not procedural fluency only. Increasing learner choice and assisting teachers in their supporting role may create the need for different types of problems.

Boaler (2014, p. 2) refers to mathematics problems that give learners 'space to learn'. This article sought to look at some aspects of opening this 'space'. The element of choice appears to be evident in creating a sense-making space. Although this idea emanated from a models and modelling perspective, it may be possible to transfer it to define significant pedagogical spaces in other areas of mathematical teaching and learning.

The article set out to conceptually describe sense-making in mathematics classrooms and to understand some of its features. The description or highlighted features are not an all-encompassing account. Wilson (1963) reminds us that conceptual analysis does not always result in right or wrong or complete answers but only 'a number of logical sketches of greater or less merit' which may contribute to something worthwhile (p. 48). By exploring the research questions, this article may add to our understanding of sense-making but does not produce a 'one size fits all' definition' (Kahn \& Zeidler, 2017, p. 542). From the field of mathematical modelling it appears that sense-making is enhanced because complex problems are devolved (Brousseau, 1997) to learners and the model construction process is largely a decisionmaking one. Learners are engaged with choice in order to produce models. Furthermore, sense-making in mathematics classrooms is enhanced through less teacher structuring and learners using their own informal methods (which also develops cognitive flexibility). Certain types of problems may enhance sense-making through providing opportunities for learners to interpret contexts. In interpreting contexts, learners are challenged to make assumptions and engage in more significant mathematical thinking. Finally, a possible framework for understanding learner sense-making is suggested but will need further interrogating by means of conceptual and empirical research. Inductive reasoning in conceptual analysis usually results in conclusions that are likely but not certainly true (Kahn \& Zeidler, 2017).

Encouraging learner choice and freedom to get involved in mathematical discussions with peers may allow for greater levels of sense-making. Learner choice may come about in methods or representation or simply in engaging in alternative procedures or finding connections between ideas and procedures. Featuring more learner choice in lessons may involve re-negotiating the didactical contract that exists in classrooms. This necessitates that a teacher 'lets go' of doing most of the mathematical work in the classroom.

\section{Acknowledgements Competing interests}

The author declares that she has no financial or personal relationships that may have inappropriately influenced her in writing this article.

\section{References}

Artz, A.F., \& Armour-Thomas, E. (1992). Development of a cognitive-metacognitive framework for protocol analysis of mathematical problem solving in small groups. Cognition and Instruction, 9(2), 137-175. https://doi.org/10.1207/s1532690 xci0902_3

Bliss, K., \& Libertini, J. (2016). What is mathematical modeling? In S. Garfunkel \& M Montgomery (Eds.), Guidelines for assessment and instruction in mathematical Montgomery (Eds.), Guidelines for assessment and instruction in mathematical
modeling education (GAIMME) (pp. 7-22). Bedford, MA: Consortium for Mathematics and its Applications (COMAP) and Society for Industrial and Applied Mathematics and its Applications (COMAP) and Society for Industrial and Applied
Mathematics (SIAM). Retrieved from http://www.siam.org/reports/gaimme-full Mathematics (SIAM). Retrieved
color_for_online_viewing.pdf

Blomhoj, M., \& Jensen, T.H. (2007). What's all the fuss about competencies? In W. Blum, P. Galbraith, H. Henn, \& M. Niss (Eds.), Modelling and applications in mathematics education. 14th ICMI Study (pp. 45-57). New York, NY: Springer. mathematics education. 14th ICMI Study (pp.

Boaler, J. (2014). The mathematics of hope: Moving from performance to learning in mathematics classrooms. Retrieved from https://bhi61nm2cr3mkdgk1dtaov18wpengine.netdna-ssl.com/wp-content/uploads/The-Mathematics-of-Hope-5.pdf

Boaler, J. (2015). What's math got to do with it? New York, NY: Penguin Books.

Boaler, J. (2016). Mathematical mindsets. San Francisco, CA: Jossey-Bass.

Bousso, R.S., Poles, K., \& Da Cruz, D. (2014). Nursing concepts and theories. Revista da Escola de Enfermagem da USP, 48(1), 141-145. https://doi.org/10.1590/S0080Escola de Enfermagem
623420140000100018

Brousseau, G. (1997). Theory of didactical situations in mathematics. Didactique des mathematiques, 1970-1990. Dordrecht: Kluwer Academic Publishers.

Chevallard, Y. (1989, August). On didactic transposition theory: Some introductory notes. Paper presented at the International Symposium on Selected Domains of Research and Development in Mathematics Education. Bratislava. Retrieved from http://yves.chevallard.free.fr/spip/spip/article.php3?id_article=122

Cirillo, M., Pelesko, J.A., Felton-Koestler, M.D., \& Rubel, L. (2016). Perspectives on modeling in school mathematics. In C.R. Hirsch \& A.R. McDuffie (Ed.), Annua perspectives in mathematics education 2016: Mathematical modeling and modeling mathematics (pp. 3-16). Reston, VA: NCTM.

Dewey, J. (1910). How we think. Boston, MA: D.C. Heath. https://doi.org/10.1037/ 10903-000 
Dienes, Z.P. (1971). Building up mathematics (4th ed.). London: Hutchinson Educational.

English, L., \& Watters, J.J. (2004). Mathematical modelling with young children. In M.J. Hoines \& A.B Fuglestad (Eds.), Proceedings of the 28th Conference of the International Group for the Psychology of Mathematics Education (Vol 2 pp. 335-342). Bergen, Norway: PME. Retrieved from https://files.eric.ed.gov/ fulltext/ED489632.pdf

Franke, M.L., Carpenter, T.P., Levi, L. \& Fennema, E. (2001). Capturing teachers' generative change: A follow-up study of professional development in mathematics. American Education Research Journal, 38(3), 653-689. https://doi.org/10.3102/ 00028312038003653

Fosnot, D.T., Dolk, M., Zolkower, B., Hersch, S. \& Seignoret, H. (2006). Mathematics in the city: Measuring teacher change in facilitating mathematization. Paper used at the Coaching Institute for Numeracy and Literacy Leaders.

Francisco, J.M. (2013). Learning in collaborative settings: Students building on each other's ideas to promote their mathematical understanding. Educational Studies in Mathematics, 82, 417-438. https://doi.org/10.1007/s10649-012-9437-3

Freudenthal, H. (1991). Revisiting mathematics education. China lectures. Dordrecht: Kluwer Academic Publishers.

Gravemeijer, K. (1994b). Educational development and developmental research in mathematics education. Journal for Research in Mathematics Education, 25(5), mathematics education. Journal for Resec
443-471. https://doi.org/10.2307/749485

Gravemeijer, K.P.E. (1994a). Developing realistic mathematics education. Utrecht: $\mathrm{CD} \beta$ Press.

Gann, C., Avineri, T., Graves, J., Hernandez, M., \& Teague, D. (2016). Moving students from remembering to thinking: The power of mathematical modeling. In C.R. Hirsch \& A.R. McDuffie (Ed.), Annual perspectives in mathematics education 2016: Mathematical modeling and modeling mathematics (pp. 97-106). Reston, VA: NCTM.

Hamilton, E. (2007). What changes are occurring in the king of problem-solving situations where mathematical thinking is needed beyond school? In R.A. Lesh, E. Hamilton, \& J.J. Kaput (Eds.), Foundations for the future in mathematics education (pp. 1-6). Mahwah, NJ: Lawrence Erlbaum.

Hatano, G. (1996). A conception of knowledge acquisition and its implications fo mathematics education. In L.P. Steffe, P. Nesher, P. Cobb, G.A. Goldin, \& B. Gree (Eds.), Theories of mathematical learning (pp. 197-217). Mahwah, NJ: Lawrence Erlbaum.

Hiebert, J., Carpenter, T.P., Fennema, E., Fuson, K.C., Wearne, D., Murray, H., ... Human P. (1997). Making sense: Teaching and learning mathematics with understanding Portsmouth, $\mathrm{NH}$ : Heinemann.

Hiebert, J., Gallimore, R., Garnier, H., Bogard Givvin, K., Hollingsworth, H., Jacobs, J., .. Stigler, J. (2003). Teaching mathematics in seven countries: Results from the TIMSS 1999 video study. Washington, DC: National Center for Education Statistics. Retrieved from https://nces.ed.gov/pubs2003/2003013.pdf

Jensen, T.H. (2007). Assessing mathematical modelling competency. In C. Haines, P. Galbraith, W. Blum, \& S. Khan (Eds.), Mathematical modelling. Education,
engineering and economics - ICTMA 12 (pp. 141-148). Chichester: Horwood. engineering and economics - ICTMA 12 (pp.
https://doi.org/10.1533/9780857099419.3.141

Kahn, S., \& Zeidler, D.L. (2017). A case for the use of conceptual analysis in science education research. Journal of Research in Science Teaching, 54(4), 538-551. education research. Journal of Resed
https://doi.org/10.1002/tea.21376

Kilpatrick, J. (1985). A retrospective account of the past twenty-five years of research on teaching mathematical problem solving. In E.A. Silver (Ed.), Teaching and learning mathematical problem solving: Multiple research perspectives ( $\mathrm{pp} .1-15$ ). Hillside, NJ: Lawrence Erlbaum.

Klein, G., Moon, B., \& Hoffman, R.R. (2006). Making sense of sensemaking 1: Alternative perspectives. IEEE Intelligent Systems, 21(4), 70-73. https://doi.org/10.1109/ MIS.2006.75

Kramarski, B., Mevarech, Z., \& Arami, M. (2002). The effects of metacognitive instruction on solving mathematical authentic tasks. Educational Studies in Mathematics, 49(2), 225-250. https://doi.org/10.1023/A:1016282811724

Lave, J., \& Wenger, E. (1991). Situated learning: Legitimate peripheral participation Cambridge, MA: Cambridge University Press. https://doi.org/10.1017/CBO9780 511815355

Leatham, K.R., Peterson, B.E., Stockero, S.L., \& Van Zoest, L.R. (2015). Conceptualizing mathematically significant pedagogical opportunities to build on student thinking. Journal for Research in Mathematics Education, 46(1), 88-124. https://doi.org/ 10.5951/jresematheduc.46.1.0088

Lesh, R., \& Doerr, H.M. (2003). Foundations of a models and modeling perspective on mathematics teaching, learning, and problem solving. In R. Lesh \& H.M. Doer (Eds.), Beyond constructivism: Models and modeling perspectives on mathematics problem solving, learning and teaching (pp. 3-33). Mahwah, NJ: Lawrence Erlbaum. https://doi.org/10.4324/9781410607713

Lesh, R., Yoon, C., \& Zawojewski, J. (2007). John Dewey revisited: Making mathematics practical versus making practice mathematical. In R.A. Lesh, E. Hamilton, \& J.J. Kaput (Eds.), Foundations for the future in mathematics education (pp. 315-348). Mahwah, NJ: Lawrence Erlbaum.
Mazur, E. (2013, October). Assessment, the silent killer of learning. Dudley Herschbach teacher/scientist lecture, Harvard University Cambridge, MA. Retrieved from https://www.youtube.com/watch?v=CBzn9RAJG6Q

National Council of Teachers of Mathematics. (2016). A teacher's guide to reasoning and sense making. Reston, VA: NCTM. Retrieved from https://www.nctm.org/ uploadedFiles/Standards and Positions/Focus_in_High_School Mathematics/ FHSM_TeacherGuide.pdf

Nieuwoudt, S. (2015). Developing a model for problem-solving in a Grade 4 mathematics classroom. Pythagoras, 36(2), a275. https://doi.org/10.4102/ pythagoras.v36i2.275

Pea, R.D. (1993). Practices of distributed intelligence and designs for education. In G. Salomon (Ed.), Distributed cognitions: Psychological and educational considerations (pp. 443-454). Cambridge: Cambridge University Press.

Reiley, E. (2017). Developing a mathematical modelling task for all students. In G.A Stillman, W. Blum, \& G. Kaiser (Eds.), Mathematical modelling and applications: Crossing and researching boundaries in mathematics education (pp. 443-454). Cham, Switzerland: Springer. https://doi.org/10.1007/978-3-319-62968-1_37

Reusser, K. (2000). Success and failure in school mathematics: Effects of instruction and school environment. European Child and Adolescent Psychiatry, 9(2), 17-26. https://doi.org/10.1007/s007870070006

Schoenfeld, A.H. (1991). On mathematics as sensemaking: An informal attack on the unfortunate divorce of formal and informal mathematics. In J.F. Voss, D.N. Perkins, \& J.W. Segal (Eds.), Informal reasoning and education (pp. 311-343). Hillsdale, NJ: Lawrence Erlbaum.

Schoenfeld, A.H. (1992). Learning to think mathematically: Problem solving, metacognition and sense making in mathematics. In D.A. Grouws (Ed.), Handbook of research on mathematics teaching and learning (pp. 334-370) New York, NY: MacMillan. Retrieved from http://hplengr.engr.wisc.edu/Math Schoenfeld.pdf

Schoenfeld, A.H. (2014). Mathematical modeling, sense making, and the common core state standards. In B. Dickman \& A. Sanfratello (Eds.), Proceedings of the Conference on Mathematical Modeling (pp. 13-25). New York, NY: Program in Mathematics and Education, Teachers College, Columbia University. Retrieved from https://docplayer.net/64493160-Conference-on-mathematical-modeling. html

Schoenfeld, A.H., \& the Teaching for Robust Understanding Project. (2016). An Introduction to the Teaching for Robust Understanding (TRU) Framework Berkeley, CA: Graduate School of Education. Retrieved from http://map.mathshell. org/trumath.php or http://tru.berkeley.edu

Sierpinska, A. (1994). Understanding in mathematics. London: Falmer Press.

Soltis, J.F. (1978). An introduction to the analysis of educational concepts (2nd ed.). Reading, MA: Addison-Wesley

Stein, M.K., Engle, R.A., Smith, M.A. \&, Hughes, E.K. (2008). Orchestrating productive mathematical discussions: Five practices for helping teachers move beyond show and tell. Mathematical Thinking and Learning, 10, 313-340. https://doi.org/ and tell. Mathematical Think
10.1080/10986060802229675

Tabachneck, H.J.M., Koedinger, K.R., \& Nathan, M.J. (1994). Toward a theoretical account and strategy use and sense-making in mathematics problem solving. In A. Ram \& K. Eiselt (Eds.), Proceedings of the 16th Annual Conference of the Cognitive Ram \& K. Eiselt (Eds.), Proceedings of the 16th Annual Conference of the Cognitive
Science Society (pp. 836-841). Atlanta, GA: Erlbaum. Retrieved from https:// Science Society (pp. 836-841
philpapers.org/rec/TABTAT

Treffers, A. (1987). Three dimensions: A model of goal and theory description in mathematics instruction - The Wiskobas project. Dordrecht: Reidel. https://doi. mathematics instruction - The Wist
org/10.1007/978-94-009-3707-9

Treilibs, V., Burkhardt, H., \& Low, B. (1980). Formulation processes in mathematical modelling. Nottingham: Shell Centre for Mathematical Education.

Trzcienieka-Schneider, I. (1993). Some remarks on creating mathematical concepts. Educational Studies in Mathematics, 24(3), 257-264. https://doi.org/10.1007/ BF01275426

Van Velzen, J.H. (2016). Evaluating the suitability of mathematical thinking problems for senior high-school students by including mathematical sense making and global planning. The Curriculum Journal, 27(3), 313-329. https://doi.org/10.1080/09585 176.2016.1174140

Webb, D.C., Boswinkel, N., \& Dekker, T. (2008). Beneath the tip of the iceberg: Using representations to support student understanding. Mathematics Teaching in the Middle School, 14(2), 110-113.

Weick, K.E., Sutcliffe, K.M., \& Obstfeld, D. (2005). Organizing and the process of sensemaking. Organization Science, 16(4), 409-421. https://doi.org/10.1287/ orsc.1050.0133

Wilson, J. (1963). Thinking with concepts. New York, NY: Cambridge University Press.

Zawojewski, J.S., Lesh, R., \& English, L. (2003). A models and modeling perspective on the role of small group learning activities. In R. Lesh \& H.M. Doerr (Eds.), Beyond constructivism: Models and modeling perspectives on mathematics, problem solving, learning, and teaching (pp. 337-358). Mahwah, NJ: Lawrence Erlbaum. 